\title{
Carbon Measurement: An Overview of Forest Carbon Estimation Methods and the Role of Geographical Information System and Remote Sensing Techniques for REDD+ Implementation
}

\author{
Thakur Bhattarai ${ }^{1}$, Margaret Skutsch ${ }^{2}$, David Midmore ${ }^{3}$ and Him Lal Shrestha ${ }^{4}$ \\ ${ }^{1,3}$ School of Medical and Applied Science, CQ University-Australia, ${ }^{2}$ University of Twente-Netherlands, \\ ${ }^{4}$ International Centre for Integrated Mountain Development (ICIMOD)-Nepal, \\ Corresponding author: t.bhattarai@cqu.edu.au
}

\begin{abstract}
Many scientists and policy makers consider payment for environmental services, particularly carbon payment for forest management, a cost-effective and practical solution to climate change and unsustainable development. In recent years an attractive policy has been discussed under the United Nation Framework Convention on Climate Change (UNFCCC): Reducing Emissions from Deforestation and Forest Degradation (REDD+), sustainable management of forest, and conservation and enhancement of carbon in developing countries. This could potentially reward forest-managing communities in developing countries. One of the challenging tasks for the successful implementation of this policy is setting up reliable baseline emissions scenarios based on the historical emissions as input for business as usual projections. Forest biomass measurements, the quantification of carbon stocks, their monitoring, and the observation of these stocks over time, are very important for the development of reference scenario and estimation of carbon stock. This paper reviews a numbers of methods available for estimating forest carbon stocks and growth rates of different forest carbon pools. It also explores the limitations and challenges of these methods for use in different geographical locations, and suggests ways of improving accuracy and precision that reduce uncertainty for the successful implementation of REDD+. Furthermore, the paper assesses the role of remote sensing (RS) and geographical information system (GIS) techniques in the establishment of a long-term carbon inventory.
\end{abstract}

Key words: Deforestation and forest degradation, carbon stock, emission, remote sensing

\section{INTRODUCTION}

Payment for Reducing Emissions from Deforestation and forest Degradation, sustainable management of forest, and conservation and enhancement of carbon in developing countries (REDD+) has been attracting world attention as it could potentially reward forest-managing communities in the developing countries who manage local forests in a sustainable way such that biomass levels increase. The central idea of REDD+ is performance-based payments that can be established for reducing emissions or enhancing forest carbon stocks (Angelsen 2008). One of the major challenges for generating carbon incentives is that it requires a sound and transparent measurement, reporting and verification (MRV) system that can estimate the changes in the forest carbon stocks sufficiently and accurately. This paper first considers the scale at which payments can be made for REDD+ crediting. It continues with a discussion of tools and techniques used for MRV, and finally concludes that there is a role of remote sensing (RS) techniques to improve effectiveness and efficiency of MRV.

The scale at which carbon is accounted and credited, and REDD + incentives are granted is one of the most prominent issues in the current United Nations Framework Convention on Climate Change (UNFCCC) negotiation. For this, three different options are being discussed: a national level, a project level, and a nested approach (mix of two) (Figure 1). The project-level approach emphasizes finer geographic and temporal scales of measurement of carbon stocks and changes, in which credits directly flow to the forest managers or forest managing communities. At the national scale, credits flow to the national 
government based on the performance against the set national baseline level. In the nestedapproach, countries can start with a subnational approach and scale up to a national level over time. These two approaches have slightly different data requirements, using different measurement tools and techniques.
For optimum accuracy and precision, projectlevel approach may rely mostly on the field measurements while national-level monitoring may use RS techniques to provide extensive coverage and simultaneously detect changes in forest cover.

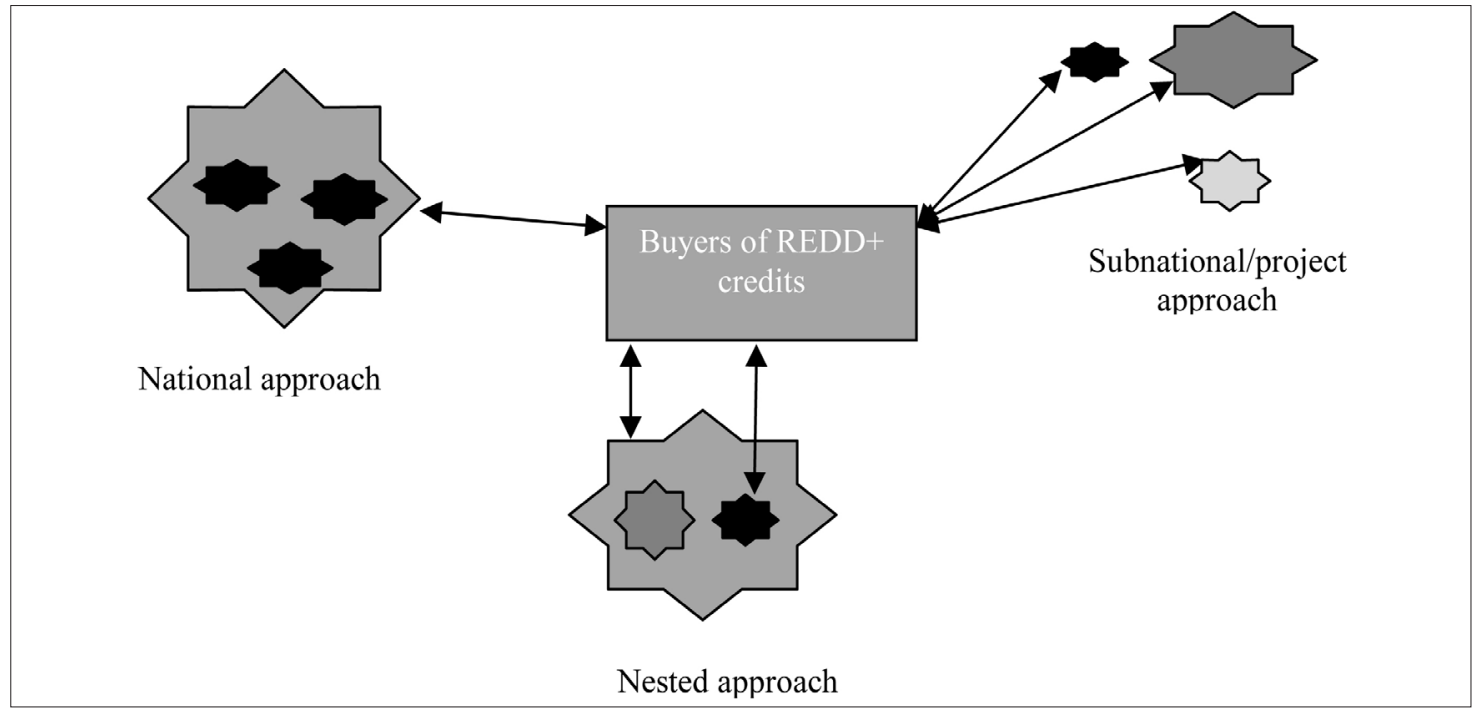

Figure 1: Potential Geographical Scales of REDD+ Accounting and Crediting

Source: Adapted from Angelsen (2008)

The national-level approach would likely be in place for REDD+ accounting to avoid the risk of within-country leakage (leakage is an increase in carbon dioxide $\left(\mathrm{CO}_{2}\right)$ emissions in one area results reduction of $\mathrm{CO}_{2}$ in another country or region due to REDD+ activities) and enhance overall emissions reductions (Chomitz et al. 2007), and to improve forest monitoring and management (Skutsch et al. 2008). This approach helps countries develop a stronger sense of ownership on REDD+. Discussions among parties of the UNFCCC are largely focused on the idea of a national approach, and the REDD+ Readiness plans that have been submitted to the World Bank's Forest Carbon Partnership Facility (FCPF) and the United Nations Collaborative Programme on REDD (UN-REDD+) programme have all adopted this position.
Setting up a reference level for the national approach and repeated MRV for crediting is a challenging task because of the wide range of variations in forest types, forest management practices, geographical locations, soil types and resource requirements. This article reviews the existing carbon assessment methods and explores the possibilities of remote sensing techniques for the effective implementation of REDD+. The general understanding is that REDD+ activities need to offer economic incentives that encourage forest managers or governments to keep their forest intact. If the incentives are to be output related, a scientifically robust measurement method that fulfils the characteristics shown in Table 1 is absolutely essential. These characteristics moreover are necessary in order to support claims for crediting of the carbon internationally. 
Table 1: Good Practice for Forest Carbon Accounting

Accuracy and

Precision

Comparable

Comprehensiveness

Conservative

Consistent

Relevance

Transparent
Accuracy is how close the estimates are to the true value; accurate measurements lack due to bias and systematic error. Precision is the level of agreement between repeated measurements; precise measurements have lower random error. To give confidence in the estimate, both accuracy and precision are desirable and can be increased through removal of bias and reduction in uncertainty as far as possible

The data, methods and assumptions applied in the accounting process must be those with widespread consensus and which allow meaningful and valid comparisons between areas

Accounting should be inclusive of all relevant categories of sources and sinks and gases, as limited accounting may lead to misleading results. If carbon pools or gases are excluded, documentation and justification for their omission must be presented (for example, for the purposes of conservative estimates)

Where accounting relies on assumptions, values and procedures with high uncertainty, the most conservative option in the biological range should be chosen not to overestimate sinks or underestimate sources of greenhouse gases (GHGs). Conservative carbon estimates can also be achieved through the omission of carbon pools

Accounting estimates for different years, gases and categories should reflect real differences in carbon rather than differences in methods

Recognising that trade-offs must be made in accounting as a result of time and resource constraints, the data, methods and assumptions must be appropriate to the intended use of the information

The integrity of the reported results should be able to be confirmed by a third party or external actor. This requires sufficient and clear documentation of the accounting process to be available so that credibility and reliability of estimates can be assessed

Sources: Pearson et al. (2005); IPCC (2003, 2006)

\section{ASSESSING DEFORESTATION AND FOREST DEGRADATION}

There is no single method to assess carbon stock changes across all landscapes. A number of guidelines and methods have been developed for monitoring and verification of forest carbon estimation. The major guidance resources available for national level forest carbon accounting are the Intergovernmental Panel on Climate Change (IPCC) guidelines (IPCC 2003, 2006) and GOFC-GOLD (2008), which have been reviewed e.g. by Gibbs et al. (2007).

Monitoring and verification of REDD+, as indicated by Ramankuttty et al. (2007), requires five different sets of data: 1) the aerial extent of deforestation and forest degradation in hectares; 2) for degradation, the percentage or proportion of biomass within the forest; 3) the location of the deforestation or forest degradation losses (in what forest type); 4) the carbon content of each forest type in tonnes per hectare; and 5) the process of forest loss which affects the rate and timing of emissions.

\section{Deforestation}

There are different methods available that can accurately measure deforestation at the national 
level. The selection of appropriate monitoring methods depends on the magnitude of deforestation, bio-geographic characteristics (seasonality of forests, relief and cloud coverage) and costs. According to DeFries et al. (2007), RS is the only practical method for monitoring national-level deforestation. Wallto-wall mapping and sampling methods are two common approaches to measure entire forests. An entire country's image is analysed in the wall-to-wall approach whereas sampling methods use systematic sampling technique. These approaches do not exclude each other as the sampling approach can be extended in one reporting period to wall-to-wall mapping in the subsequent period, and wall-to-wall technique can also be followed up by the sampling analysis in the subsequent period.

Until now, the use of the RS technologies has not only been expensive but also technically challenging for data analysis, and the error and uncertainty are not always well characterised (Gibbs et al. 2007). A stepwise approach is the simplest way to reduce the costs in which course resolution data [e.g. Moderate Resolution Imaging Spectroradiometer (MODIS)] are analysed to identify locations with high rates of land use change (deforestation hotspots). Later on more costly medium-fine resolution data (e.g. Landstat, Satellite Pour l'Observation de la Terre (SPOT), Synthetic aperture radar (SAR) can be used to conduct detailed analysis of these hotspots. This approach reduces the need to analyse the entire forested area within a country.

The most crucial components of MRV are accuracy and verification of the results. About 80 to 95 per cent accuracy can be obtained by the use of medium-resolution image (e.g. Landsat) for monitoring, particularly to differentiate between forests and nonforests. For assessing accuracy, either ground observations or analysis of fine resolutions aircraft or satellite imaging can be used. Aerial photography presents a more adaptable tool for verification, as fine-resolution imagery remains expensive. The accuracy and precision of the MRV of deforestation can be further assessed through peer-review by third party (DeFries et al. 2007). For the monitoring purposes, continuously updated data through Google Earth can be another source of free viewable fine-resolution imagery of up to 50 $\mathrm{cm}$ resolution (Olander et al. 2008).

\section{Forest Degradation}

Forest degradation is another major source of emissions. It shrinks forest sequestration capacity, and reduces the ability of forest to provide ecosystem services and the livelihood benefits to local communities (Murdiyarso et al. 2008).

The measurement of forest degradation is much more difficult than that of deforestation (DeFries et al. 2007). This is because of the complex mix of different land cover types (species, age, dead trees, soil type, shade, aspect, altitude) and the wide range of human interferences (GOFC-GOLD 2008). There are several causes of forest degradation that need to be addressed to achieve a real emission reduction target through the REDD+ mechanism. The major causes requiring monitoring are mentioned in Table 2.

The RS methods may only be useful for quantifying advanced stages of forest degradation where removals of biomass lead to detectable gaps in the forest canopy, which is typically the case for selective logging or fire. However, Murdiyarso et al. (2008) state that forest degradation by removing a few trees (selective logging), by understory grazing and removal of non-timber forest products and fuel wood collection cannot be observed remotely; these need ground measurement techniques. Ground measurement can complement RS techniques especially when degradation does not create gaps in the canopy, such as with the collection of deadwood and understorey vegetation and other typical community uses of forest products (Hardcastle and Baird 2008). 
Table 2: Causes of Degradation and Impact on Monitoring

Causes of forest Monitoring feasibility
degradation

Remote sensing methods using medium resolution imagery can detect gaps in the forest canopy caused by roads and log decks

Selective logging Reduction in carbon stocks can also be estimated without satellite imagery using methods from the 2006 IPCC GL-AFOLU, although it is more difficult to estimate emissions from logging

Forest fires

More difficult to monitor with existing satellite imagery, but possible to build on existing fire information for REDD+ uses

Over-exploitation of fuel wood and other non-timber forest products

Likely to be undetectable from the satellite image interpretation unless the rate of degradation is intensive, causing larger changes in the canopy Inventory-based approaches (field surveys) may be more appropriate

Mining

Difficult to monitor as forest openings are often too small to be detected

Source: Adapted from GOFC-GOLD (2008)

According to Achard et al. (2008), there are two main RS approaches that are currently being used to monitor forest degradation: direct and indirect approaches. The direct approach detects gaps in forest canopies whereas the indirect approach is used to detect road networks and log decks (Achard et al. 2008). While monitoring selective logging and fire, the direct approach employs automated algorithms for assessing logging activities by using Landsat data that monitors forest canopy for any gaps or patterns of gaps to identify degradation activity (Asner et al. 2005). Roy et al. (2005) also developed a methodology to map fire-affected areas using MODIS data. An accuracy of 86 to 95 per cent has been shown to be achievable in the interpretation of selectively logged and burned areas (Achard et al. 2008).

The indirect approach for monitoring forest degradation classifies forestlands into 'intact forest' (fully stocked, no disturbance) and 'non-intact forest' (disturbed due to timber exploitation and other activities that reduce the forest biomass), which also depends on the national circumstances (Achard et al. 2008). Simply, forest degradation is the conversion of the intact forest to non-intact forests, and emissions from forest degradation of these areas can be estimated from the difference in carbon content between intact and non-intact forests. The major weakness of this method is carbon differences between an intact to a slightly disturbed forest may be lower than going from a slightly disturbed to severely disturbed forest.

\section{ASSESSING FOREST CARBON STOCKS AND CHANGES \\ Approaches for Estimating Carbon Stock Changes}

The stock-difference and gain-loss approaches are the two fundamentally different, but equally valid approaches for the measurement of carbon stock change (Brown and Braatz 2008). In the stock-difference approach, carbon stocks are physically measured using sampling for each forest carbon pool over a certain time interval e.g. $\mathrm{t}_{1}$ and $\mathrm{t}_{2}$ (Figure 2). In the gain-loss approach, both gains and losses of different pools will be estimated based on assumptions about off-take and growth rates. These two approaches are based on the key assumption that the flows of $\mathrm{CO}_{2}$ to or from the atmosphere are equal to the changes in carbon stocks. 
The stock-difference approach with stratified sampling techniques (dividing forest into homogenous blocks based on the age, species and landscape or similar parameters) would be more cost effective and suitable for estimating carbon stock difference for intact forests because it is easier to account for changes in the stocks of all the relevant pools than measuring all carbon uptake and carbon release (IPCC 2006). The loss-gain approach is generally suitable for the countries with large areas of forests under logging concessions (Murdiyarso et al. 2008) where physical sampling is difficult.

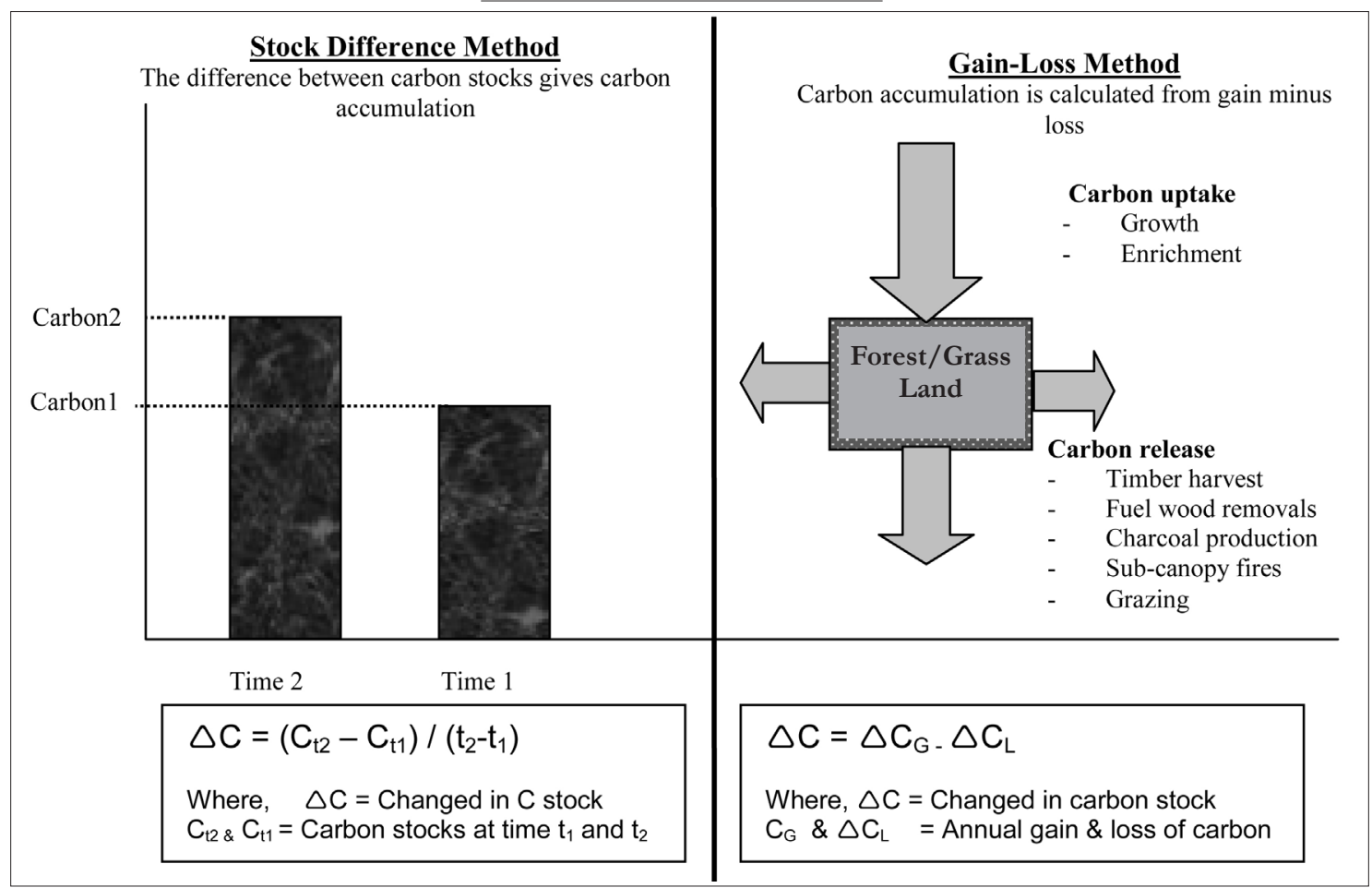

Figure 2: Estimating Carbon Stock Changes

Source: Adapted from Murdiyarso et al. (2008)

\section{Intergovernmental Panel on Climate Change (IPCC) tiers}

The IPCC Guidelines for Agriculture, Forestry and Other Land Use (AFOLU) of 2000 have grouped different methods for three different hierarchical tiers with different levels of complexities (Figure 3).
Tier 1 offers the simplest to use alternative that utilises globally available activity data (e.g. on deforestation rates). Equations and default values (e.g. emission and stock change factors) are provided by IPCC (2006). 


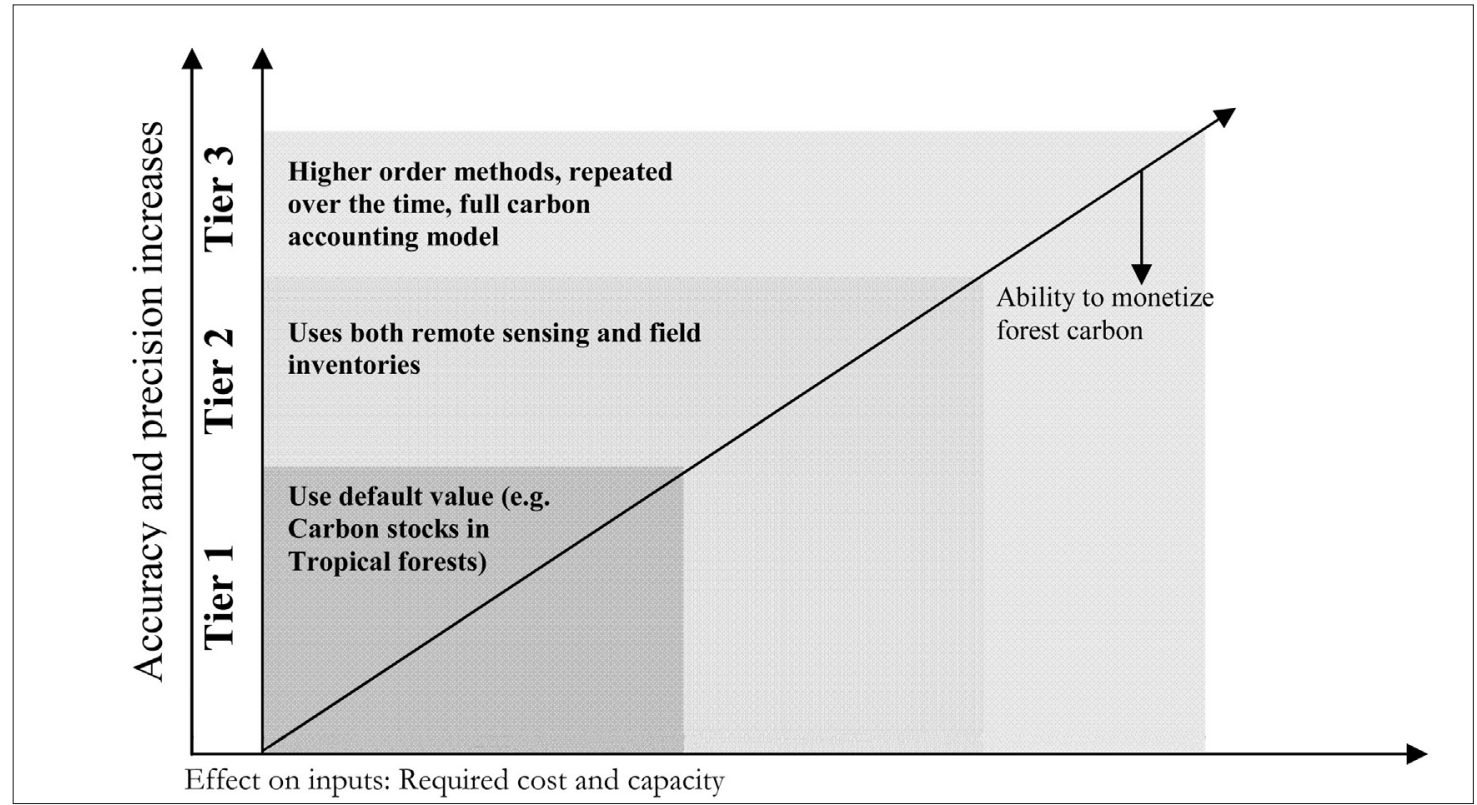

Figure 3: Overview of the Effects of Achieving Higher Quality Estimates.

Source: Adapted from Havemann (2009)

Tier 1 reporting is recommended for with limited availability of country-specific data. However, Tier 1 estimates may not qualify for reporting in the scope of REDD+ due to large error rates, which are in the range of plus or minus 50 per cent (Hardcastle and Baird 2008). Moving to higher tiers (tiers 2, 3) reduces the uncertainty of estimates but increases the complexity and cost of the utilised monitoring and reporting systems. In order to be flexible for implementation of the country level, good practice guidance needs to be followed. The selection of the tier depends on the type of carbon pools, area coverage (local or national level), costs, time and the level of accuracy and precision required.

\section{Forest Carbon Pools}

Biomass and soil organic carbon are the two major forest carbon pools. Biomass pools can be further divided into living above ground biomass (AGB) (tree and under-story vegetation), below ground biomass (BGB) roots, dead biomass of litter and wood debris (Figure 4). The biomass is expressed in tonnes of biomass (dry matter) per hectare, which is then converted into carbon multiplying by 0.5 (Houghton 2003; IPCC 2006). Soil organic carbon is held in soils as organic matter, humidified material and in stable structure such as charcoal, and is also expressed at tonnes of carbon per hectare. In addition, harvested wood products (HWP) are also sometimes considered as a carbon pool in some cases, particularly for national GHG inventories (IPCC 2006). 


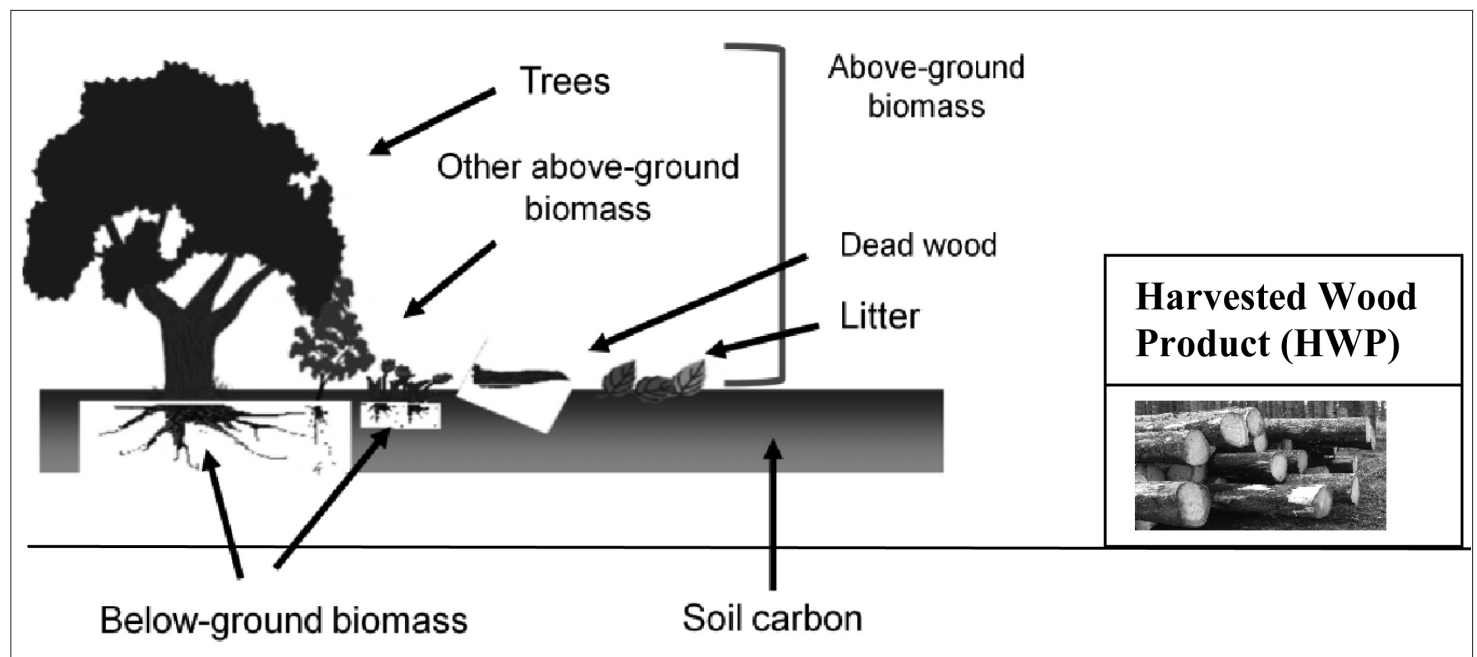

Figure 4: Carbon Pools in Forest and Grassland Ecosystems

Source: IPCC 2006

Forest trees generally represent the largest portion of the total biomass (e.g. Cairns et al. 1997; Chave et al. 2005; MacDicken 1997; Segura and Kanninen 2005), although this depends very much on the ecosystem. Almost all the carbon stock is indeed in the trees in tropical rainforests while carbon in the roots and in the soil may exceed than in the trees in savanna woodlands. For example, MacDicken (1997) reports that BGB varies significantly from 4 to 230 per cent of the above ground tree biomass because of high variation between species, climatic conditions and other external factors. BGB, dead wood and fine litter comprise about 3 per cent, 5 to 40 per cent and 5 per cent of the above ground tree biomass respectively (MacDicken 1997). The major methods and techniques used for AGB are briefly discussed below.

\section{Methods for Estimating Carbon Pools}

Since there are a number of $\mathrm{C}$ estimation methods available for the estimation of different forest carbon pools (Table 3), an appropriate method needs to be selected for the most accurate results.

\section{Above Ground Biomass (AGB)}

AGB represents all biomass in living vegetation, both woody and herbaceous which is above the soil. This is in many cases, though not all, the most visible and important carbon pool in the most land-based projects. Methods available for estimation and monitoring of the AGB pool are briefly discussed.

Plot Method: This is a simple, cost-effective method, which is extensively used in forest inventory for estimating and monitoring carbon stock change. The principle of this method is to estimate the volume or weight of tree and non-tree biomass in a set of sample plots using the measured values of parameters such as diameter at breast height $(\mathrm{DBH})$ and height of tree and applying generic allometric equations which relate $\mathrm{DBH}$ and height to volume. This method is suitable for both sparse and dense vegetation and applicable for both monoculture and diverse vegetation. It is a commonly used method which is described in many sources such as the IPCC Guidelines (2003, 2006), Brown and Masera (2003), Chave 
et al. (2005), MacDicken (1997), Pearson et al. several manuals have also been developed by (2007) and Winrock International (1999) and national and international organisations.

Table 3: Methodological Options for Estimating Forest Carbon and their Suitability

\begin{tabular}{|c|c|c|}
\hline Pools & Methods & Suitability for carbon measurement \\
\hline \multirow{6}{*}{ 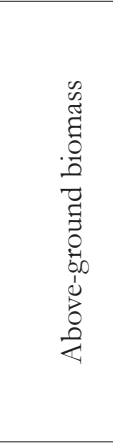 } & Plot method & Very suitable and cost-effective, commonly adopted and familiar \\
\hline & Harvest method & Expensive, time consuming, not appropriate all the times \\
\hline & Plot-less or transect method & $\begin{array}{l}\text { Good but not suitable in dense vegetation and for periodic } \\
\text { monitoring }\end{array}$ \\
\hline & Modelling & $\begin{array}{l}\text { Suitable for projections } \\
\text { Requires basic input parameters }\end{array}$ \\
\hline & Carbon flux measurements & Expensive and needs skilled human resources \\
\hline & Satellite/remote & $\begin{array}{l}\text { Expensive for small projects and not suitable yet for multiple land } \\
\text { use system }\end{array}$ \\
\hline \multirow{3}{*}{ 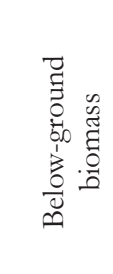 } & $\begin{array}{l}\text { Root extraction and weight } \\
\text { measurement }\end{array}$ & Expensive and not suitable \\
\hline & $\begin{array}{l}\text { Root to shoot ratio or } \\
\text { conservation factor }\end{array}$ & $\begin{array}{l}\text { Most commonly used } \\
\text { Requires AGB measurement }\end{array}$ \\
\hline & Biomass equations & Requires input data e.g. height, diameter, girth \\
\hline \multirow{2}{*}{ 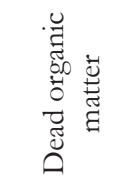 } & Litter trap & Not always suitable and requires huge effort \\
\hline & Stock measurement & Feasible and commonly adopted \\
\hline \multirow{3}{*}{$\begin{array}{l}\text { है } \\
\text { है } \\
\text { है } \\
=\overline{0} \\
\infty\end{array}$} & Diffuse reflectance spectroscopy & Expensive and requires skilled manpower \\
\hline & Modelling & Suitable for projection, requires input data from other methods \\
\hline & Laboratory estimation & $\begin{array}{l}\text { Most suitable, commonly adopted and familiar method but very } \\
\text { expensive and time consuming }\end{array}$ \\
\hline
\end{tabular}

Source: Ravindranath and Ostwald (2008)

Harvest method is the most comprehensive and accurate method to estimate the woody and non-woody biomass stock. However, it is very costly and only suitable to develop location and species-specific allometric equations and calibrate models (Ravindranath and Ostwald 2008).

Modelling is mostly used for future projecting of carbon stocks of different commercial plantation as well as forest types. It is used to supplement field methods, where indicators of carbon stocks are measured and estimated.
Plot-less or transect method: In this method, tree density and $\mathrm{DBH}$ along a series of parallel sample lines is measured to calculate tree biomass using biomass equations. This method is appropriate for grassland with sparse tree density and suitable for single period estimation.

Carbon flux measurements involve installing a chamber to enclose a small area or a particular component (e.g. soil, stems or leaves) and provide an estimate of mass and energy exchange between vegetation surfaces 
and the atmosphere. Then it allows direct and non-destructive measurement of net exchange of $\mathrm{CO}_{2}$ comprising its uptake via photosynthesis and loss through respiration, evaporation and sensible heat. This is accurate, yet expensive and not feasible for large-scale carbon assessment.

Remote sensing is useful for estimating forest area but most of the techniques do not yet provide an alternative to the traditional methods for estimating carbon stocks and growth rates because of resolution issues and because much of the change in forest stock occurs below the canopy. Advance technologies such as Light Detection and Ranging (LiDAR) and Radio Detection and Ranging (RADAR) do offer opportunities but at present they are prohibitively expensive and require technical skills, and institutional capacity as well. As indicated earlier, standard RS technology can accurately monitor deforestation but is not capable of quantifying the carbon of all landscapes. Remote sensing for advanced carbon estimation is described more in a latter section of the paper.

There are many improvements that could be made to estimate tree AGB more precisely and accurately. For example, most existing allometric equations were developed to estimate wood volume for timber purposes, so the focus has been on valuable trees and on trees with diameter more than $10 \mathrm{~cm}$. From a carbon point of view, all trees are valuable, and a wider range of equations is therefore needed. Also, most allometric equations are based on the trees that were harvested in the 1960s, and it could be questioned whether forms of tree growth have remained the same, given ongoing climate change.

\section{Below Ground Biomass (BGB) Estimation}

Direct measurement, default root to shoot ratio values and allometric equations are the commonly used methods for estimating BGB (Table 4). Direct measurement of total root biomass is very expensive, destructive and time consuming due to the variation of root distribution in the soil, and there is no standard practical method yet designed (Cairns et al. 1997). If site specific equations are not available for particular species, default value can be used. The conservative ratio, $0.10-0.15$ of the total AGB is often used to calculate below ground tree biomass as recommended by 2006 IPCC Guidelines.

The available database for BGB is limited and does not cover all the conditions of latitude, soil texture, age, tree type, and AGB. Also, greater attention needs to be given to the measurements of coarse and butt roots, which account for the largest proportion of root biomass [(on average 70 per cent or more of the total root biomass (Cairns et al. 1997)]. Therefore, rigorous experimental designs using common methods need to be adopted, particularly for coarse and butt root biomass.

\section{Dead Organic Matter}

This pool contains deadwood (both standing as well as fallen) and floor litter. The coarse deadwood, both lying and standing, is very important and can represent up to 10 to 20 per cent of the AGB in the mature forests, however it is often ignored in accounting grassland and young forests (Harmon and Sexton 1996). The litter pool represents a small proportion ( $<10$ per cent) of the total tree biomass (Ravindranath and Ostwald 2008).

The deadwood and litter biomass pools are generally estimated by employing an appropriate sampling method similar to the plot methods, and then that is multiplied by an expansion factor used to represent the area. The litter in the sample plot is collected, dried, weighed and calculated to carbon.

\section{Soil Organic Carbon}

At a global level, soil is the largest reservoir of the carbon and represents 80 per cent of the total terrestrial supplies (Ravindranath and Ostwald 2008). The accumulation of Soil Organic Carbon (SOC) is affected by climatic 
factors (Post et al. 1999; Kurz et al. 1996); landscape, soil texture and aggregation and management practices amongst others.

Methods to estimate SOC are well established and documented (Post et al. 1999). Soil depth, soil bulk density and concentrations of organic carbon are the three major variables measured in the estimation. The available methods to estimate concentrations of organic carbon include dry combustion or loss ignition, wet digestion (Walkley and Black method), diffuse reflectance spectroscopy, colorimetry and modelling. Wet digestion is the most common and cost-effective method to estimate soil organic carbon. One of the difficulties is however, assessing change in soil carbon over time, since this tends to be slow. Moreover, it is not clear that if losses occur, the carbon has been transferred to the atmosphere. If the loss of organic carbon at one site is due to soil erosion, the carbon may simply have been transferred down the catena.

\section{Estimating Uncertainty in Carbon Accounting}

A key challenge of terrestrial carbon inventory is uncertainty in estimating AGB. Chave et al. (2004) highlighted that there are mainly three types of errors associated with AGB estimation: sampling error (the variation among sampling methods and units e.g. the number of plots within the population), measurements error (error in measuring parameter such as stem diameter, tree height and soil carbon) and selecting appropriate allometric models. Sampling error is usually the largest source of error and can account for more than 90 per cent of the total error, and increased precision generally comes at increasing cost of establishing the appropriate sampling techniques and number of plots and appropriatedistributionin the entireecosystem. Stratification of the project area into more or less homogeneous units and selection of appropriate allometic equations based on vegetation type, soil type, land-use history, or topography, can increase acceptable levels of precision. The common parameters for AGB estimation are trunk height and diameter, however, diameter alone is sometime more suitable as height measurement is impossible in a dense forest when it is difficult to see tree apex (Williams and Schreuder 2000). Allometric equations may also be a source of error if they are inappropriate for the species and site, but if permanent sampling plots and the same trees are used every time the survey is done, these errors will not be very important as it is the change in biomass that is important rather than the total. The higher the tier used, the better the precision and accuracy. IPCC guidelines, including several carbon measurement manuals, suggest 95 per cent confidence interval for the uncertainty estimation in both individual variables and final carbon estimation. IPCC guidelines have described in detail how to minimise potential bias and error in the carbon inventory.

\section{Decision Matrix}

Selection of pools for forest carbon estimation depends on the nature and objectives of the project, size of the pool, the rate of carbon stock changes, availability of estimation methods, measurement costs and attainable accuracy and precision (IPCC 2003; MacDicken 1997). For example, dead wood would be an important pool for mature forest but not for young plantation and agro-forestry (Table 4). As payment for REDD+ is likely to be performance-based, the cost factors of MRV play an important role in deciding whether the inclusion of the particular pool is profitable and reasonable to measure. Hence, only those carbon pools should be considered that are changing considerably due to REDD+ activities and which can be monitored costefficiently. For example, accounting for the herbaceous pool may sometimes be relatively more expensive as it requires similar amount of resources for tree measurement but the absolute biomass change is low compared to that of trees. 
Table 4: Decision Matrix for the Measurement of the Primary Carbon Pools

\begin{tabular}{|c|c|c|c|c|c|c|c|}
\hline \multirow{3}{*}{ Activity } & \multicolumn{7}{|l|}{ Carbon pools } \\
\hline & \multicolumn{3}{|l|}{ Living biomass } & \multicolumn{2}{|c|}{ Dead Biomass } & \multirow[t]{2}{*}{ Soil } & \multirow{2}{*}{$\begin{array}{l}\text { Wood } \\
\text { products }\end{array}$} \\
\hline & $\begin{array}{l}\text { Above-ground } \\
\text { tree }\end{array}$ & $\begin{array}{l}\text { Above-ground } \\
\text { non-tree }\end{array}$ & $\begin{array}{l}\text { Below } \\
\text { ground }\end{array}$ & Litter & $\begin{array}{l}\text { Dead } \\
\text { wood }\end{array}$ & & \\
\hline $\begin{array}{l}\text { Improve forest } \\
\text { management (REDD+) }\end{array}$ & Y & M & $\mathrm{R}$ & M & $\mathrm{Y}$ & M & M \\
\hline REDD+ & Y & M & $\mathrm{R}$ & M & M & M & Y \\
\hline Plantation & Y & $\mathrm{N}$ & $\mathrm{R}$ & M & M & $\mathrm{R}$ & Y \\
\hline Afforestation & Y & M & Y & M & M & Y & M \\
\hline Agroforestry & $\mathrm{Y}$ & M & Y & $\mathrm{N}$ & $\mathrm{N}$ & Y & $\mathrm{M}$ \\
\hline
\end{tabular}

Where, $\mathrm{Y}=$ Yes: should be measured; $\mathrm{M}=$ May be needed; $\mathrm{R}=$ Recommended, $\mathrm{N}=$ No: Not necessary to measure

Source: Adapted from Brown et al. (2000)

\section{REMOTE SENSING FOR FOREST CARBON ESTIMATION}

Ground measurement of forestry parameters leads to biomass estimation (Bhattarai et al. 2012) but for reasons of the constrained access and extract of area to be sampled, field surveys are not always suitable. This is where Tier 3 methodologies come into play, using remote sensing imageries. The spectral (Teillet et al. 1997) as well as the spatial resolution (Nichol and Sarker 2011) of satellite imageries are important when achieving precise biomass estimations using compatible wall-to-wall products with mapping compatibility.

The methodologies adopted for the quantification of forest biomass based on remote sensing data depend on the characteristics of the satellite images that are used. The characteristics of remote sensing data may vary in terms of sensor types (active or passive); spectral characteristics [(Panchromatic (PAN), Multispectral Scanner (MSS), Hyperspectral] and spatial characteristics $(0.5 \mathrm{~m}, 1 \mathrm{~m}, 5.6 \mathrm{~m}, 10 / 15 \mathrm{~m}$, $30 \mathrm{~m}, 250 \mathrm{~m}, 1 \mathrm{~km}$ ) (Lillesand et al. 2007). The lower the spatial resolution, the more generalized estimate that can be generated from the remote sensing data; conversely the higher the spatial resolution, the more precise data that can be generated. Enhanced spectral preciseness enables interpretation of the hypo-spectral information that exists in the image. That is mainly due to the segregation of response from the vegetation across the different light wavelengths, i.e., Blue, Green, Red, Near Infrared (NIR), Short-wave Infrared (SWIR), FWIR, Thermal Infrared (TIR) bands in Landsat MSS images.

\section{Monitoring Deforestation}

IPCC GPG (2003) and IPCC (2007) have suggested the priority for monitoring deforestation in the developing countries, where the social systems and interaction with the natural resources are in transition.

GOFC GOLD (2010) has shown that various methods can be applied for the monitoring of deforestation which has been realised because of the social pressure on forests in its various forms such as illegal cutting, clear felling, fuel wood demand, etc. Nepal has also shown the methods on the temporal monitoring of deforestation using the Landsat images for the Terai region from 1990 to 2000 (DoF 
2005) and it shows the comparable results with some limitations on the classification of forest types.

\section{Forest Cover Change}

Forest cover change can be monitored using inputs from various sources such as historical records and recent analysis. The uses of Landsatimages to monitor forest cover changes over time is used widely because of its free availability at fine resolution and high temporal resolution. Landsat images from previous missions and from the current mission of Landsat 8 are available for download. Archived SPOT images that are older than five years are also freely available, which will contribute to forest cover monitoring in the future.

As per the IPCC guideline (2007), the forest cover changed over a time period can comprise forest remaining as forest, forest converted to other land use type (loss), and other land use converted to forest (gain). The fact is that if one monitors deforestation with the past study data and current analysis, there will be some level of inconsistency because of the definitions, the technological shifts or other reasons too. A convenient way to approach forest cover change analysis to support deforestation analysis is to use remote sensing data, which captures the historical trends of resource dynamics. By applying consistent methods across temporarily spaced imageries, one can quantify the changes in the forest cover over time. Therefore, the remote sensing process provides a convenient opportunity to analyse the spatial and temporal variability of forest cover.

\section{Mapping Degradation of Forest Areas}

Forest degradation can be quantified as the inverse function of forest growth. Forest growth can be defined by the Mean Annual Increment (MAI) after the analysis of the dominant forest species. If the forest MAI increases, in general terms, it is an evidence for forest growth. In contrast, if the MAI of the particular forest decreases, it can be said that forest growth is declining. Then, the status of the forest is degraded. Before the quantification of forest degradation, there should be calculated activity data of forest degradation that could show where the forest is actually degraded.

Remote sensing images can provide the opportunity to quantify forest degradation. The degradation is quantified as the change in the forest canopy density. Current attempts are ongoing for the canopy density mapping using Landsat TM data for the years 1990, 2000 and 2010 in Nepal. As examples, through the use of high resolution satellite imagery such as GeoEye and WorldView images with $0.5 \mathrm{~m}$ spatial resolution, detection and the delineation of the crown projection area (CPA) through the application of object based image analysis (OBIA) technique at the watershed level estimation of the rates of forest degradation between two dates has been achieved (Karna et al. 2015; Hussin et al. 2014; Purity et al. 2014)..

\section{Biomass Estimation Using Remote Sensing}

Biomass and carbon stock estimation of the forest stand is the next step when estimating the reduction in total emissions due to avoided deforestation and forest degradation. The various deforestation manifestations such as conversion from/to forests and forest degradation such as reduced forest growth or degradation by area will have different emission factors.

Remote Sensing has the capability to support the quantification of $\mathrm{AGB}$ and carbon as it detects and quantifies the forest areas using the reflectance from the forest captured by the sensor providing satellite imagery. But the contribution of satellite imagery can vary 
based on the spectral and spatial resolution. For example Lands at Thematic Mapper (TM) has $30 \mathrm{~m} * 30 \mathrm{~m}$ pixels and 7 bands for detection of forest resources, and WorldView and GeoEye images have at least $0.5 \mathrm{~m}$ pixel size with 4 bands.

The quantification of above the ground forest carbon using medium resolution Landsat images can be done with the following calculations of the reflectance values from the forest conditions. The field measured biomass/carbon is correlated with the corresponding average normalized difference vegetation index (NDVI) values of the plot by overlaying the plots supported by Global Positioning System (GPS) tracking of sample plot locations from the field.

The High-Resolution Satellite Imageries (HRSI) provide the opportunity to quantify the above-ground forest carbon at higher precision and at micro-levels such as for small community forests and other small patches of forests. This method of forest carbon quantification requires a level of sophisticated image processing to delineate the individual trees from the HRSI. OBIA image segmentation and image classification technique supports tree delineation, as trees are viewed vertically by the size of crown of the trees. Therefore, HRSI provides the opportunity to map individual trees. The field measured individual trees' above-ground carbon can then be further correlated with the corresponding crown mapping of the same trees. The GPS tracking of individual trees must be established to develop allometric equations between the remote sensing based on crown projection area index to the individual tree-based carbon estimates for further estimating the forest stand. For this, the use of the differential GPS method is appropriate to locate trees.

\section{LiDAR Assisted Monitoring System}

Arbonaut Ltd has adopted Lidar Assisted Multisource Program (LAMP) as a method of forest inventory including the tools ArboLidar to estimate the forest biomass over the forest stand. The method incorporates not only the Airborne Lidar Scanning (ALS) data for the forest biomass estimation, it also includes field measurement, Landsat metrics and RapidEye indices as input for the precise estimation of the forest biomass considering it as a multisource forest inventory technique.

The research for incorporating LiDAR data is to obtain estimated tree heights with remotely estimated interoperable digital height data, which is assumed to be better than the ground based estimation of height. The field measurements of basal area of forest is done with the digital LiDAR based height to estimate forest biomass with precision (Gautam et al. 2013; Hussin et al. 2014). Satellite imagery and LIDAR data permits OBAI that can lead to particular spares level classification and carbon stock of forest stands (Karna et al. 2015).

\section{RADAR Data Used for the Biomass Estimation}

Another method, which is frequently used for biomass estimation at forest stand structure level is that with radardata. Itincorporates radar interferometry to estimate the above-ground tree height using microwave technology. The RADAR data with polarization in horizontal and vertical combinations precisely detects the height of the tree with the digital capability to integrate with other data. The analysis of the RADAR data requires more strands and specialized software that use satellite imagery and could be followed by polarization, interferometry and interpretation with RADAR image processors. 


\section{Spatially Explicit Carbon Flux}

The spatial activity data on deforestation and reforestation and the activity data on forest regrowth and degradation may be further animated using the spatially interpreted biomass and carbon stocks over time of carbon flux study. The spatially explicit carbon flux product is the output from this analysis that allows one to see the spatial distribution of carbon flux at spatial and temporal domain, which ultimately supports timely precise decision-making and planning.

\section{General Considerations}

Remote sensing technologies are evolving day by day and therefore, there are several emerging options to use satellite images for carbon estimation of above-ground forest e.g. very high resolution data, radar, and LiDAR based data (Gibbs et al. 2007). Optical and passive satellite images present many variations in terms of sensors, data types, coverage, storage and resolution. The spatial resolution varies from $0.5 \mathrm{~m}$ (GeoEye Image) to $30 \mathrm{~m}$ (Landsat image) (Olander et al. 2008). The sensor itself may be active or passive. Passive sensors work in the presence of sunlight and give the reflectance values (Land Sat, Quick Bird, IKONOS, GeoEye etc). Active sensors such as radar and LiDAR do not use light but emit their own source of energy and receive images in non-optical forms. An advantage of this is that radar and LiDAR are able to 'see' through clouds. Another property of the remote sensing images is the dimensionality; normally remote sensing has two dimensions but the capability of remote sensors to capture data with the possibility of stereoscopic viewing allows the possibility of obtaining a third dimension (altitude) too. As a result, digital elevation models can be generated from satellite imageries.

Considerable research has taken place with such new methodologies for the measurement of forest dimensions and above-ground carbon stocks. Some of the research communities believe that the advanced remote sensing procedures will be able to satisfy the requirements for accurate and precise forest volume estimation as the radar image provide height information of the stand that contributes to the estimation of growing stock in the forest. The problems with the radar data are the different perspectives of the objects and the need for capacity to handle the data from SAR interferometry. Moreover, the resolution of radar data to date is not sufficient for individual tree measurement. However, LiDAR could offer high resolution and 3D modelling capability in the long run. It can give the basal area and tree height with a high degree of precision. However, it is very expensive at present as it is airborne rather than satellite based. Also, a very high level of training and skill is needed to analyse and interpret unit radar data.

\section{CONCLUSION}

Since the REDD+ mechanism will demand precise and accurate monitoring; reporting and verification systems, RS technologies combined with ground measurement will be required to satisfy the demand for cost effectiveness and speed. The precision of the measurement of carbon as well as the monitoring technique is crucial for the credibility of REDD+ implementation. Clear and practical methodologies are needed not only in the field measurement, but also in the application of remote sensing for MRV. However, satellite and airborne imagery is very expensive and accessible only to experts which are in short supply. Development of new human resources and enhancement of the skills of existing human resources may help better supply the required services. The recent development of technology and methodologies in remote sensing (e.g. LiDAR technique and data acquisition, radar data) could contribute further to improve precision and accuracy of assessment, if their costs are reduced. 


\section{REFERENCE}

Achard, F., DeFries, R., Herold, M., Mollicone, D., Pandey, D. and de Souza Jr., C. 2008. Guidance on Monitoring of Gross Changes in Forest Area. Chapter 3 in GOFC-GOLD Reducing Greenhouse Gas Emissions from Deforestation and Degradation in Developing Countries: A Sourcebook of Methods and Procedures for Monitoring, Measuring and Reporting. GOFCGOLD Report Version COP13-2. Alberta, Canada: GOFC-GOLD.

Angelsen, A. 2008. How Do We Set the Reference Levels for REDD Payments? In: A. Angelsen. (Ed.), Moving Ahead with REDD: Issues, Options and Implications (pp. 53-64). CIFOR, Bogor, Indonesia.

Asner, G., Knapp, D.E., Broadbent, E.N., Oliveira,P.J.C., Keller M. and Silva, J. 2005. Selective Logging in the Brazilian Amazon. Science, 310: 480-482.

Bhattarai, T.P., Skutsch, M., Midmore, D.J. and Rana, E.B. 2012. The Carbon Sequestration Potential of Community Based Forest Management in Nepal. The International Journal of Climate Change: Impacts and Responses, $\mathbf{3}(2)$.

Brown, S. and Braatz, B. 2008. Methods for Estimating $\mathrm{CO}_{2}$ Emissions from Deforestation and Forest Degradation. Chapter 5 in GOFCGOLD Reducing Greenhouse Gas Emissions from Deforestation and Degradation in Developing Countries: A Sourcebook of Methods and Procedures for Monitoring, Measuring and Reporting. GOFC-GOLD Report version COP 13-2. Alberta, Canada: GOFC-GOLD.

Brown, S., Burnham, M., Delaney, M., Vaca R., Powell, M. and Moreno, A. 2000. Issues and Challenges for Forest-based Carbon-Offset Projects: A Case Study of the Noel Kempff Climate Action Project in Bolivia. Mitigation and Adaptation Strategy for Global Change, 5: 99-121

Brown, S. and Masera, O. 2003. Supplementary Methods and Good Practice Guidance Arising from the Kyoto Protocol. In: J. Penman, M. Gytartsky, T. Hiraishi, T. Krug, D. Kruger, R. Pipatti, L. Buendia, K. Miwa, T. Ngara, K. Tanabe, F. Wagner (Eds.), Good Practice Guidance for Land Use, Land-Use Change and Forestry, Intergovernmental Panel on Climate Change National Greenhouse Gas Inventories Programme. Kanagawa, Japan: Institute for Global Environmental Strategies (IGES).

Cairns, M. A., Brown, S., Helmer, E. H. and Baumgardner, G. A. 1997. Root Biomass Allocation in the World's Upland Forests. Oecologia, 111: 1-11.
Chave, J., Andalo, C., Brown, S., Cairns, M. A., Chambers, J. Q., Eamus, D., Fölster, H., Fromard, F., Higuchi, N., Kira, T., Lescure, J. P., Nelson, B.W., Ogawa, H., Puig, H., Riéra, B. and Yamakura, T. 2005. Tree Allometry and Improved Estimation of Carbon Stocks and Balance in Tropical Forests. Oecologia, 145 (1): 87-99.

Chave, J., Condit, R., Aguilar, S., Hernandez, A., Lao, S. and Perez, R. 2004. Error Propagation and Scaling for Tropical Forest Biomass Estimates. Philosophical Transactions B, 359: 409-20

Chomitz, K., M, Buys, P., de Luca, G., Thomas, T., S. and Wertz-Kanounnikoff, S. 2007. At Loggerheads? Agricultural Expansion, Poverty Reduction, and Environment in the Tropical Forests. Policy Research Report. Washington D.C: World Bank.

DeFries, R., Achard, F., Brown, S., Herold M., Murdiyarso, D., Schmlamadinger, B. and deSouza, C. 2007. Earth Observations for Estimating Greenhouse Gas Emissions from Deforestation in Developing Countries. Environmental Science and Policy, 10: 385-94.

DoF. 2005. Forest Cover Change Analysis of the Terai Districts (1990/91-2000/01). Department of Forest, Government of Nepal.

Gautam, B., Peuhkurinen, J., Kauranne, T., Gunia, K., Tegel, K., Latva-Käyrä, P., Rana, P., Eivazi, A., Kolesnikov, A., Hämäläinen, J., Shrestha, S.M., Gautam, S. K., Hawkes, M., Nocker, U., Joshi, A., Suihkonen, T., Kandel, P., Lohani, S., Powell, G., Dinerstein, E., Hall, D., Niles, J., Joshi, A., Nepal, S., Manandhar, Kandel, U. Y. and Joshi, C. 2013. Estimation of Forest Carbon Using LiDAR-Assisted Multi-source Programme (LAMP) in Nepal. Presented at International Conference on Advanced Geospatial Technologies for Sustainable Environment and Culture, 12-13 September, 2013, Pokhara, Nepal.

Gibbs, H., Brown, S., Niles, J. and Foley F. 2007. Monitoring and Estimating Tropical Forest Carbon Stocks: Making REDD a Reality. Environmental Research Letters, 2.

GOFC-GOLD. 2008. Reducing Greenhouse Gas Emissions from Deforestation and Degradation in Developing Countries: A Sourcebook of Methods and Procedures for Monitoring, Measuring and Reporting. GOFC-GOLD Report version COP13-2. Alberta, Canada: GOFCGOLD.

GOFC-GOLD. 2010. A Sourcebook of Methods and Procedures for Monitoring and Reporting Anthropogenic Greenhouse Gas Emissions and Removals Caused by Deforestation, Gains and 
Losses of Carbon Stocks in Forests Remaining Forests, and Forestation. GOFC-GOLD Report version COP 16-1. Alberta, Canada: GOFCGOLD. (http://www.gofc-gold.uni-jena.de/redd accessed on 8 October, 2014)

Hardcastle, P. D. and Baird, D. 2008. Capability and Cost Assessment of the Major Forest Nations to Measure and Monitor their Forest Carbon. Office of Climate Change. Penicuick, UK: LTS International.

Harmon, M. and Sexton, J. 1996. Guidelines for Measurements of Woody Detritus in Forest Ecosystems. US LTER Publication, 20: 1-73.

Havemann, T. 2009. Measuring and Monitoring Terrestrial Carbon. The State of the Science and Implications for Policy Makers. Forest Carbon Asia. (http://www.forestcarbonasia.org/ other-publications / measuring-and-monitoringterrestrial-carbon-the-state-of-the-science-andimplications-for-policy-makers-2/ accessed on 9 October, 2014).

Houghton, R. 2003. Why are Estimates of the Terrestrial Carbon Balance So Different? Global Change Biology, 9(4):500-509.

Hussin, Y.A., Gilani, H., Leeuwen, L.V., Murthy, M. S. R., Shah, R. and Baral, S., Tsendbazar, N.E., Shrestha, S., Shah, S.K. and Qamer, F.M. 2014. Evaluation of Object-Based Image Analysis Techniques on Very High-Resolution Satellite Image for Biomass Estimation in a Watershed of Hilly Forest of Nepal. Applied Geomatics, 6: 59-68

IPCC. 2003. Good Practice Guidance for Land Use, Land-use Change and Forestry. In: J. Penman, M. Gytarsky, T. Hiraishi, T. Krug, D. Kruger, R. Pipatti, L. Buendia, K. Miwa, T. Ngara, K. Tanabe and F. Wagner (Eds.), National GHG Inventories Programme, Institute for Global Environmental Strategies. Kanagawa, Japan.

IPCC. 2006. IPCC Guidelines for National Greenhouse Gas Inventories. In: H. S. Eggleston, L. Buendia, K. Miwa, T. Ngara, and K. Tanabe (Eds.), National Greenhouse Gas Inventories Programme, Institute for Global Environmental Strategies. Kanagawa, Japan.

IPCC. 2007. Summary for Policymakers Climate Change 2007: The Physical Science Basis. Contribution of Working Group I to the Fourth Assessment Report of the Intergovernmental Panel on Climate Change. Cambridge and New York: Cambridge University Press.

Karna, Y. K., Hussin, Y. A., Gilani, H., Bronsveld M., Murthy, M., Qamer F. M., Karky, B. S., Bhattarai T. P., Aigong X. and Baniya C. B. 2015. Integration of WorldView-2 and Airborne LiDAR Data for Tree Species Level Carbon
Stock Mapping in Kayar Khola Watershed, Nepal. International Journal of Applied Earth Observation and Geoinformation, 38: 280-291.

Kurz, W.A., Beukema, S.J. and Apps, M.J. 1996. Estimation of Root Biomass and Dynamics for the Carbon Budget Model of the Canadian Forest Sector. Canadian Journal of Forest Research, 26(11):1973-1979.

Lillesand, T.M., Kiefer, R.W. and Jonathan, C. 2007. Remote Sensing and Image Interpretation, Sixth. Ed. Toronto: John Wiley and Sons, Inc.

MacDicken, K. 1997. A Guide to Monitoring Carbon Storage in Forestry and Agroforestry Projects. Winrock International Institute for Agricultural Development.

Murdiyarso, D., Skutsch, M., Guariguata, K., Luttrell, C., Verweij, P. and Stella, O. 2008. Measuring and Monitoring Forest Degradation for REDD: Implications of Country Circumstances. CIFOR, Bogor, Indonesia.

Nichol, J.E. and Sarker, M. L. R. 2011. Improved Biomass Estimation Using the Texture Parameters of Two High-Resolution Optical Sensors, (IEEE Transactions on Geoscience and Remote Sensing, 49(3): 930-948.

Olander, L.P, Gibbs, H., K., Steininger, M., Swenson, J.J. and Murray, B., C. 2008. Reference Scenarios for Deforestation and Forest Degradation in Support of REDD: A Review of Data and Methods. Environmental Research Letters, 3: 025011.

Pearson, T., Brown, S. and Birdsay, R. 2007. Measurement Guidelines for the Sequestration of Forest Carbon. USDA Forest Service's Northern Global Change Research Program, 47.

Pearson, T., Walker, S. and Brown, S. 2005. Sourcebook for Land Use, Land-Use Change and Forestry Projects. Winrock International and the Bio Carbon Fund of the World Bank.

Post, W.M., Izaurralde, R.C., Mann, L.K. and Bliss, N. 1999. Monitoring and Verification of Soil Organic Carbon Sequestration. In: N.J. Rosenberg, R.C. Izaurralde and E.L. Malone (Eds.), Proc. Symp. Carbon Sequestration in Soils Science, Monitoring and Beyond. Columbus, $\mathrm{OH}$ : Batelle Press.

Purity, P.R.R., Hussain, Y.A., Weir, M. and Gilani, H. 2014. Quantification of Carbon Stock to Understand Two Different Forest Management Regimes in KayarKhola Watershed, Chitwan, Nepal. Journal of Indian Society of Remote Sensing, 42(4): 745-754. DOI 10.1007/s12524-014-0379-3

Ramankutty, N., Gibbs, H. K., Achard, F., DeFries, R., Foley, J. A. and Houghton, R.A. 2007. Challenges to EstimatingCarbon Emissions from 
Tropical Deforestation Global Change Biology, 13:51-66.

Ravindranath, N. and Ostwald, M. 2008. Carbon Inventory Methods: Handbook for Greenhouse Gas Inventory, Carbon Mitigation and Roundwood Production Projects. Advances in Global Change Research, 29.

Roy, D., Jin, P., Lewis, E. and Justice, C.O. 2005. Prototyping a Global Algorithm for Systematic Fire-Affected Area Mapping Using MODIS TimeSeries Data. Remote Sensing of Environment, 97: 137162

Segura, M. and Kanninen, M. 2005. Allometric Models for Tree Volume and Total Above Ground Biomass in a Tropical Humid Forest in Costa Rica. Biotropica, 3: 2-8.

Skutsch, M., Bird, N., Trines, E., Dutschke, M., Frumhoff, P., de Jong, B. H. J., Van Laake, P.,
Masera, O. and Murdiyarso, D. 2008. Clearing the Way for Reducing Emissions from Tropical Deforestation. Environmental Science and Policy, 10(4): 322-334.

Teillet, P.M., Staenz, K. and William, D.J. 1997. Effects of Spectral, Spatial, and Radiometric Characteristics on Remote Sensing Vegetation Indices of Forested Regions. Remote Sensing of Environment, 61: 139-149. http://dx.doi. org/10.1016/S0034-4257(96)00248-9.

Williams, M. and Schreuder, H. 2000. Guidelines for Choosing Volume Equations in the Presence of Measurement Error in Height. Canadian Journal of Forest Research, 30: 306-310.

Winrock International. 1999. Field Tests of Carbon Monitoring Methods in Forestry Projects. Forest Carbon Monitoring Program. Arlington, VA: Winrock International. 